\title{
Treatment outcomes of patients with localized anal squamous cell carcinoma according to HIV infection: systematic review and meta-analysis
}

\author{
Marcos Pedro Guedes Camandaroba ${ }^{1}$, Raphael Leonardo Cunha de Araujo ${ }^{2,3}$, Virgílio Souza e Silva ${ }^{1}$, \\ Celso Abdon Lopes de Mello ${ }^{1}$, Rachel P. Riechelmann ${ }^{1}$ \\ ${ }^{1}$ Department of Clinical Oncology, A.C. Camargo Cancer Center, Sao Paulo, SP, Brazil; ${ }^{2}$ Department of Digestive Surgery, Escola Paulista de \\ Medicina, Universidade Federal de São Paulo, São Paulo, SP, Brazil; ${ }^{3}$ Department of Oncology, Americas Medical Service/Brazil, United Health \\ Group, Sao Paulo, SP, Brazil \\ Contributions: (I) Conception and design: RP Riechelmann; (II) Administrative support: None; (III) Provision of study materials or patients: MP \\ Camandaroba; (IV) Collection and assembly of data: MP Camandaroba, VS Silva; (V) Data analysis and interpretation: MP Camandaroba, RL \\ Araujo, CA Mello, RP Riechelmann; (VI) Manuscript writing: All authors; (VII) Final approval of manuscript: All authors. \\ Correspondence to: Prof. Rachel P. Riechelmann, MD, PhD. Department of Clinical Oncology, A.C. Camargo Cancer Center, Rua Antônio Prudente \\ 211, São Paulo, SP, Brazil. Email: rachel.riechelmann@accamargo.org.br.
}

Background: Definitive chemoradiation (CRT) is the standard treatment for localized squamous cell carcinoma of the anus (SCCA). Because most phase III trials in SCCA have excluded patients with HIV, the evidence on treatment outcomes of these patients is lacking. We performed a systematic review and metaanalysis on the efficacy and toxicity profiles of HIV-positive SCCA patients treated with definitive CRT.

Methods: The systematic search was conducted Embase, Medline, Cochrane Libary, Scopus, Lilacs and Opengrey, from inception until September 2017. Eligible studies were clinical trials, prospective or retrospective cohort studies. The main outcome variables were 3-year disease-free survival (DFS) and overall survival (OS) rates and frequency of grade 3 or $4(\mathrm{G} 3 / 4)$ treatment-related toxicities, according to HIV status. Meta-analyses using pooled risk ratios were performed for binary outcomes from comparative studies from the antiretroviral therapy (HAART) era with the fixed effects model.

Results: Out of 3,951 studies, 40 were deemed eligible, with a total of 3,720 patients. One third (N=1,298; $34 \%$ ) were HIV-positive and their median pre CRT CD4 count was $347 \mu \mathrm{m} / \mathrm{L}$. HIV-positive patients presented higher risk of $\mathrm{G} 3 / 4$ cutaneous toxicities [risk ratio $(\mathrm{RR})=1.34 ; 95 \% \mathrm{CI}, 1.10-1.64 ; \mathrm{P}=0.004$; $\mathrm{I}^{2}=77.7 \%$, worse 3 -year DFS rate $\left(\mathrm{RR}=1.32 ; 95 \% \mathrm{CI}, 1.01-1.74 ; \mathrm{P}=0.043 ; \mathrm{I}^{2}=52.19 \%\right)$, and 3-year OS rate $\left(\mathrm{RR}=1.77 ; 95 \% \mathrm{CI}, 1.35-2.32 ; \mathrm{P}<0.001 ; \mathrm{I}^{2}=6 \%\right)$.

Conclusions: Patients with localized SCCA and HIV infection treated with CRT tend to experience higher risk of toxicities and worse DFS and OS rates. Our findings suggest that future trials should be tailored to HIV-positive patients.

Keywords: Anal cancer; human immunodeficiency virus (HIV); toxicity; survival

Submitted Aug 20, 2018. Accepted for publication Oct 11, 2018.

doi: 10.21037/jgo.2018.10.08

View this article at: http://dx.doi.org/10.21037/jgo.2018.10.08

\section{Introduction}

Squamous cell carcinoma of the anus (SCCA) is an uncommon malignancy that accounts for $2.5 \%$ of all digestive tumors (1). The main risk factor for SCCA is chronic infection from the human papilloma virus (HPV), concomitant or not with the human immunodeficiency virus (HIV) infection $(2,3)$. Recent epidemiological studies have demonstrated that there is a 20 -fold increase in the 
risk of anal cancer in individuals with HIV infection compared to the general population without HIV $(4,5)$. And AIDS diagnosis was associated with close to a fourfold increased incidence of anal cancer compared with HIV only (6). The anal cancer risk associated with HIV infection is particularly high among men who have sex with men (6). Among these individuals, a low CD4 count, immunosuppression and HPV infection seems most important at early stages in the development of anal cancer $(4,6)$.

The standard treatment for localized anal cancer is based on infusional 5-fluorouracil (5-FU) or capecitabine (7), mitomycin (MMC) or cisplatin, concomitant with external radiation. This provides excellent results with overall local control rates greater than $80 \%(2,8)$. However, HIVpositive patients have not been represented in most phase III trials that have defined the standard treatment for localized SCCA. Therefore, the evidence to guide the best treatment for these patients is lacking.

Historically, prior to antiretroviral therapy (HAART), HIV-positive patients had clear worse prognosis and experienced worse toxicities from definitive chemoradiation (CRT) compared to immunocompetent patients $(9,10)$. While HAART has increased the survival of patients with HIV $(11,12)$, studies on treatment outcomes from CRT for SCCA according to HIV status have reported variables results in terms of recurrence and survival (2,13-15). Therefore, we have undertaken a systematic review and meta-analyses about the efficacy and toxicity of CRT among patients with localized SCCA according to HIV status.

\section{Methods}

Systematic review of studies that reported clinical outcomes associated with definitive CRT (regimens of infusional $5 \mathrm{FU}$ or capecitabine with or without MMC or cisplatin combined with external radiation) for patients with histologically proven localized SCCA and HIV infection, regardless of the description of HAART use. The definition of HIV infection was serology positivity as reported by studies, with or without the clinical diagnosis of acquired immunodeficiency syndrome.

Eligible studies were clinical trials, prospective or retrospective cohort studies, without any restrictions on language. We excluded case reports, review articles, articles on patients with in situ anal carcinoma or dysplasia.

\section{Search strategy}

The search for eligible studies was performed in Embase, Medline, Cochrane Libary, Scopus, Lilacs and Opengrey databases, all from inception until September 20, 2017. In Embase, the search words were "anus tumor" OR "anus cancer" AND "human immunodeficiency virus infection". In Medline we used the MeSH terms "anus neoplasm" AND "HIV". In Cochrane Library, Scopus, Lilacs and Opengrey database we used words "anus neoplasm" OR "anus cancer" AND "HIV". We also sought the reference lists of selected articles to improve the search strategy.

Articles with less than ten patients as well as those that included patients prior to the HAART era (before 1996 or that stated so) were included in the systematic review but excluded from all pooled analyses. When such information was not provided, we considered the studies of the HAART era when they enrolled patients from 1996 (onset of HAART worldwide).

\section{Outcome measures}

To indirectly compare our results with the landmark phase III trials of CRT in localized SCCA and because most recurrence occur within 2 to 3 years from definitive chemoradiation, we selected the 3-year disease-free survival (DFS) rate, according to HIV status, as the primary endpoint. Secondary endpoints were 3- and 5-year overall survival (OS) rates, 3-year colostomy free survival rate, complete response rate at 6 months and rates of $\mathrm{G} 3 / 4$ toxicities; we limited our analysis of adverse events to G3/4 types because we assumed this information is more reliable, given that underreporting and/or difficulty in determining the relationship of G1/2 toxicities are inherent to retrospective studies.

\section{Data collection}

Two investigators (MPGC and RPR) developed the search strategy and defined the eligible studies. From each study, two investigators (MPGC and VSS) independently collected clinical information, clinical stage, type of study (comparative $v s$. non-comparative; prospective or retrospective) and treatment outcomes, according to HIV status. They compared their data to control for errors and a third investigator (RPR) was consulted in case of discrepancies. The variables were defined $a$ priori through a dictionary of word meaning. 


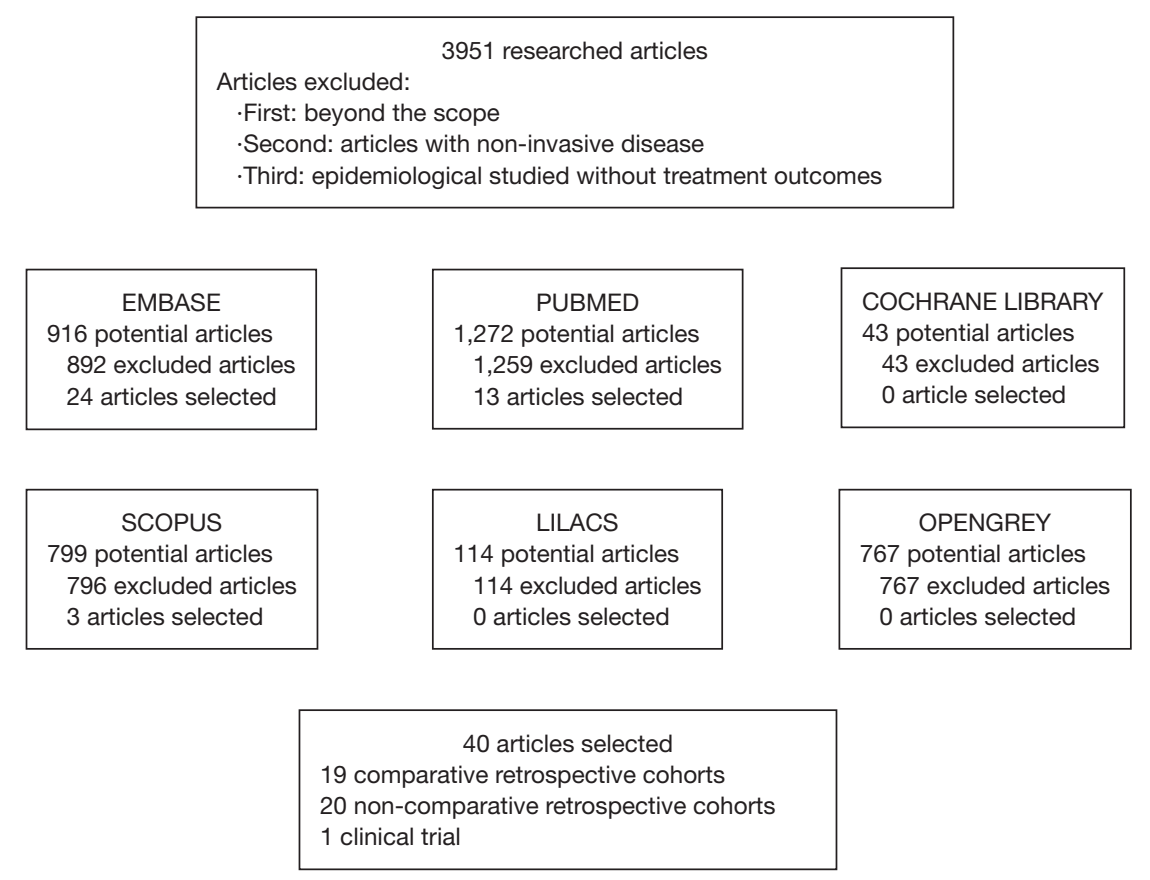

Figure 1 Flow chart of the search for eligible studies.

This systematic review was in accordance with the Preferred Reporting Items for Systematic Review and Meta-Analyses (PRISMA) statement (16).

\section{Statistical analysis}

Descriptive statistics were used to summarize the characteristics of eligible studies. Meta-analyses using pooled risk ratios were performed for binary outcomes from comparative studies with the fixed effect model. Analyses utilizing random effects were also performed and can be found as supplemental materials. To evaluate the presence of publication bias in comparative studies, we have used the Begg's funnel plot approach $(17,18)$. For non-comparative studies, funnel plots for proportion were used to identify potential presence of publication bias using a Web-based software tool developed by APHO (Association of Public Health Observatories, www.apho.org.uk). Metaprop analysis based on pooled estimates of proportions with corresponding $95 \%$ confidence intervals $(95 \% \mathrm{CI})$ were calculated on the base of the Freeman-Tukey double arcsine transformation for non-comparative data (19). All analyses were performed by STATA 13 statistical software (StataCorp, College Station, TX, USA). A two-tailed $\mathrm{P}$ value of less than 0.05 was considered statistically significant. An $\mathrm{I}^{2}$ value of less than $50 \%$, was considered significant, i.e., low probability of heterogeneity of result across studies.

\section{Results}

A total of 3,951 articles were retrieved from our initial search. As demonstrated by Figure 1, 40 studies were deemed eligible, with a total of 3,720 patients. The characteristics of studies are summarized in Table 1. Twenty studies were retrospective cohorts comparing groups of patients with and without HIV infection, 19 were retrospective studies of only HIV-positive patients; one was a phase II clinical trial of cetuximab combined with chemoradiation that included HIV-positive patients. The oldest article was from 1991 and the most recent one was from 2017, with 30 reporting the inclusion of patients who received HAART.

Nearly one third of patients ( $N=1,298 ; 34 \%)$ were HIVpositive. The median age was 44 years in the HIV-positive group vs. 62 years in the HIV-negative group. In the HIVpositive group, $93 \%$ were male and their median CD4 count prior to CRT was $347 \mu \mathrm{m} / \mathrm{L}$. Seven articles described ethnicity: 74\% were conducted in Caucasians (range, $23-$ 89\%), 33\% included African-descendants (range, 8-77\%). Clinical stage was described in 24 articles, with clinically positive lymph nodes being present in similar proportions between the HIV groups. Treatment regimens employed were: single agent $5 \mathrm{FU}, 5 \mathrm{FU}$ plus MMC, $5 \mathrm{FU}$ plus 
Table 1 Characteristics of eligible articles

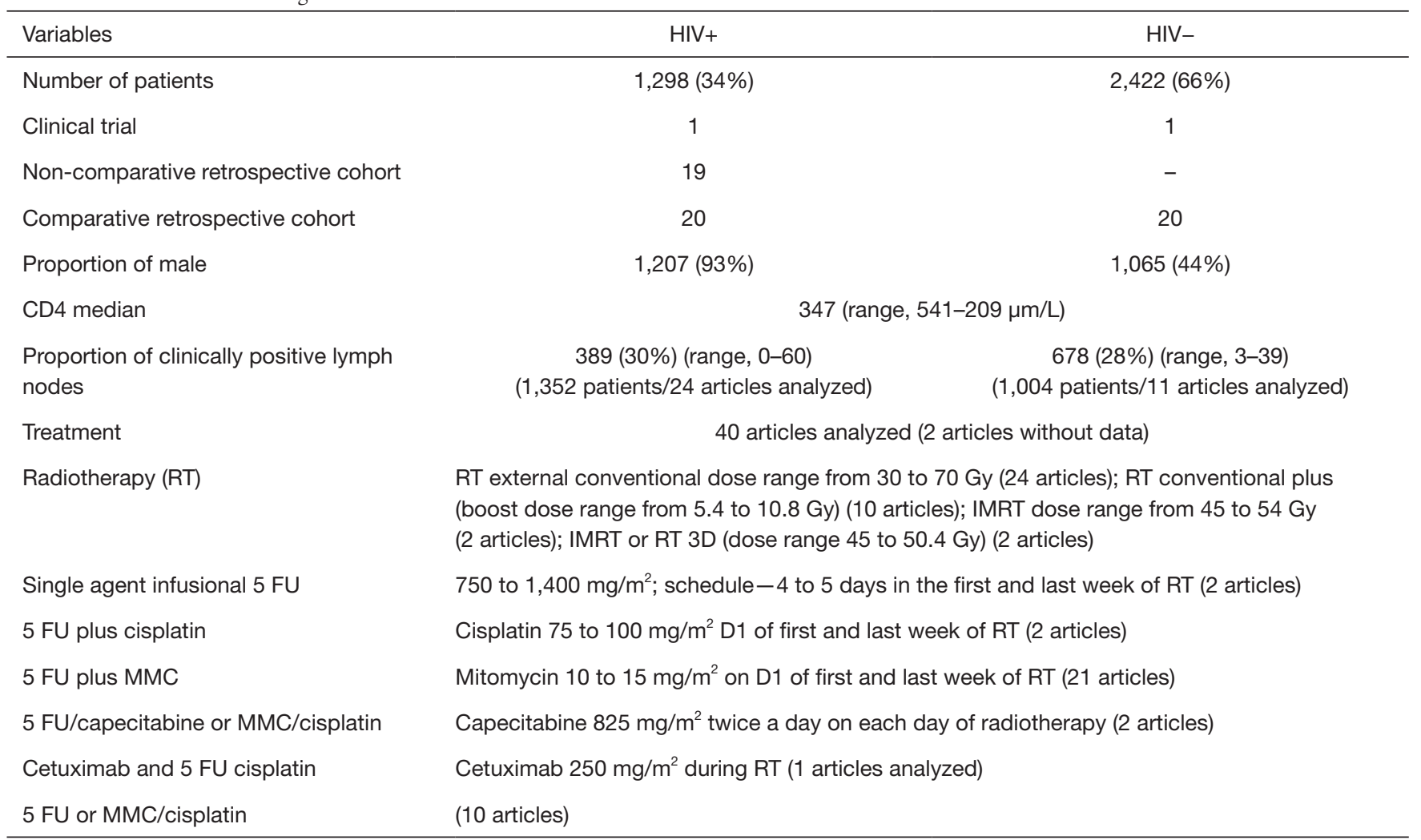

cisplatin and weekly cetuximab (Table 1).

\section{Treatment outcomes: toxicities}

Most studies reported dose reductions of chemotherapy and/or radiotherapy. Dose reductions were numerically higher in the HIV-positive patients in 7 of 10 articles who analyzed this factor. The proportion of dose-reductions ranged from $77 \%$ to $22 \%$ in the HIV-positive group and from $54 \%$ to $7 \%$ in the HIV-negative group.

The most prevalent G3/4 toxicities in HIV-positive patients were cutaneous (mostly radiation-induced dermatitis), hematological and gastrointestinal. The rates of $\mathrm{G} 3 / 4$ cutaneous toxicities ranged from $77 \%$ to $8 \%$ in HIV-positive patients and from $54 \%$ to $3 \%$ in the HIVnegative group. The meta-analysis for this G3/4 toxicity was performed only in comparative studies $(\mathrm{N}=8)$, reporting data from 876 patients (Figure 2) and showing a significantly higher risk in the HIV-positive group, with a risk ratio (RR) of 1.34 (95\% CI, 1.10-1.64; $\mathrm{P}=0.004 ; \mathrm{I}^{2}=77.7 \%$ ). Random effect analysis is shown in Figure S1.

The definition of hematological toxicity varied across studies and only leukopenia and thrombocytopenia were analyzed here (more available data). The meta-analysis for G3/4 leukopenia was performed only in comparative studies $(\mathrm{N}=3)$, reporting data from 470 patients (Figure 3). G3/4 leukopenia tended to be higher in the HIV-positive group with a RR of 1.26 (95\% CI, 0.95-1.68; $\left.\mathrm{P}=0.115 ; \mathrm{I}^{2}=0 \%\right)$. Random effect analysis is shown in Figure $S 2$.

In the HIV-positive group, G3/4 thrombocytopenia was seen more frequently as compared to HIV-negative group with a trend for statistical significance $(\mathrm{RR}=1.62 ; 95 \% \mathrm{CI}$, 0.97-2.70, $\mathrm{P}=0.064 ; \mathrm{I}^{2}=17.13 \%$ ) (Figure 3). Random effect analysis is shown in Figure S3. The meta-analysis for G3/4 thrombocytopenia was performed only in comparative studies $(\mathrm{N}=4)$, reporting data from 561 patients (Figure 4).

The rate of G3/4 gastrointestinal toxicities ranged from $31 \%$ to $2 \%$ in HIV-positive patients while in HIV-negative patients, it ranged from $17 \%$ to $3 \%$. The meta-analysis for $G 3 / 4$ gastrointestinal toxicities was performed only in comparative studies $(\mathrm{N}=5)$, reporting data from 650 patients (Figure 5). There was no difference between the groups, with a RR of 0.93 (95\% CI, 0.56-1.56; $\mathrm{P}=0.786 ; \mathrm{I}^{2}=48.1 \%$ ). Random effect analysis is shown in Figure S4. 


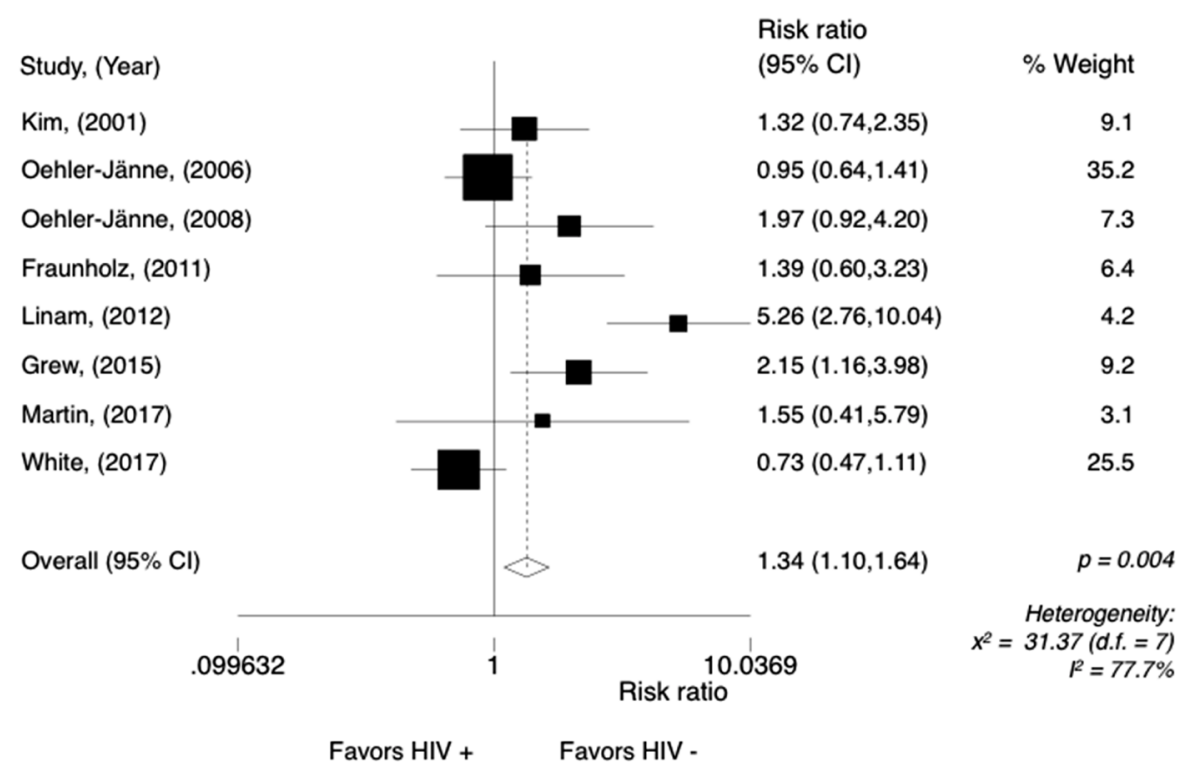

Figure 2 Forest plot of G3/4 cutaneous toxicities in comparative studies.

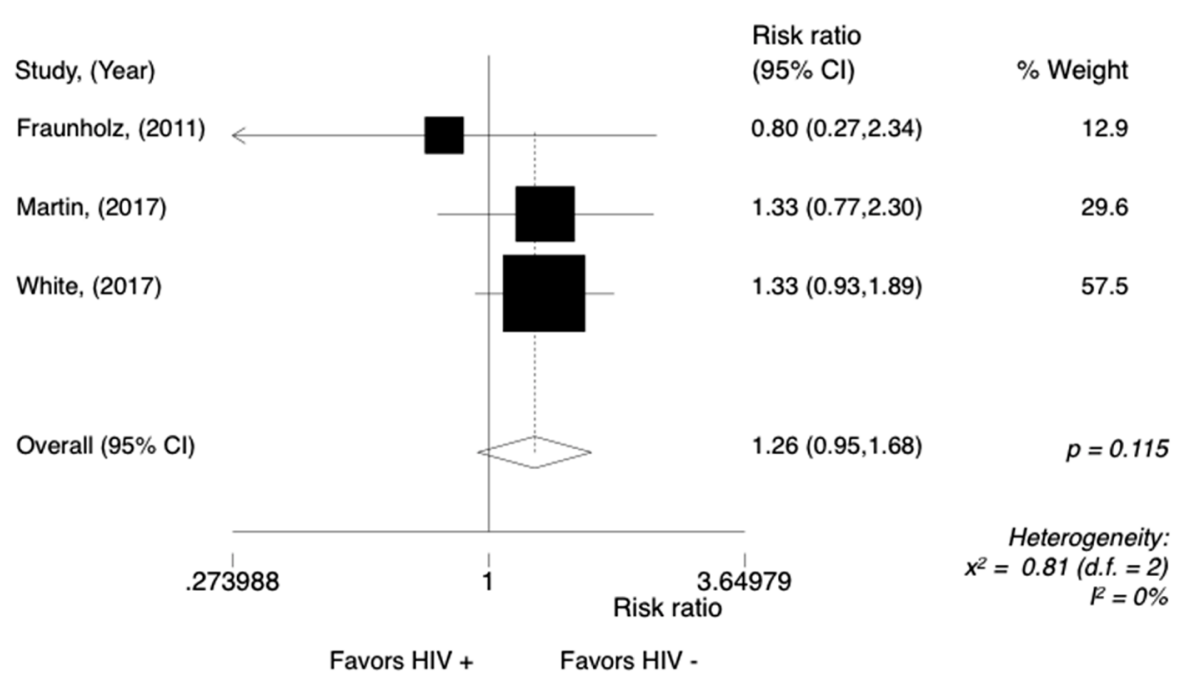

Figure 3 Forest plot of leukopenia G3/4 toxicities in comparative studies.

\section{Treatment outcomes: survival endpoints}

The 3-year DFS rate, our primary endpoint, ranged from $94 \%$ to $33 \%$ among HIV-positive patients, and from $91 \%$ to $67 \%$ among HIV-negative patients. In the noncomparative studies (Figure 6), the pooled 3-year DFS rate for HIV-positive patients was $75 \%$ (95\% CI, 64-84\%; $\left.\mathrm{P}=0.12 ; \mathrm{I}^{2}=45.24 \%\right)$. The meta-analysis for the 3 -year DFS rate performed in comparative studies $(\mathrm{N}=7)$ reports data from 686 patients. Analysis of the survival between the groups (Figure 7) showed that HIV-positive patients were significantly less likely to be DFS at 3 years with a RR 1.32 (95\% CI, 1.01-1.74; $\mathrm{P}=0.043 ; \mathrm{I}^{2}=52.19 \%$ ). Random effect analysis is shown in Figure $S 5$.

The OS rate at 3 years in the HIV-positive group ranged from $85 \%$ to $25 \%$ and in the HIV-negative group, from $92 \%$ to $58 \%$. The meta-analysis for overall 3 -year OS rate 


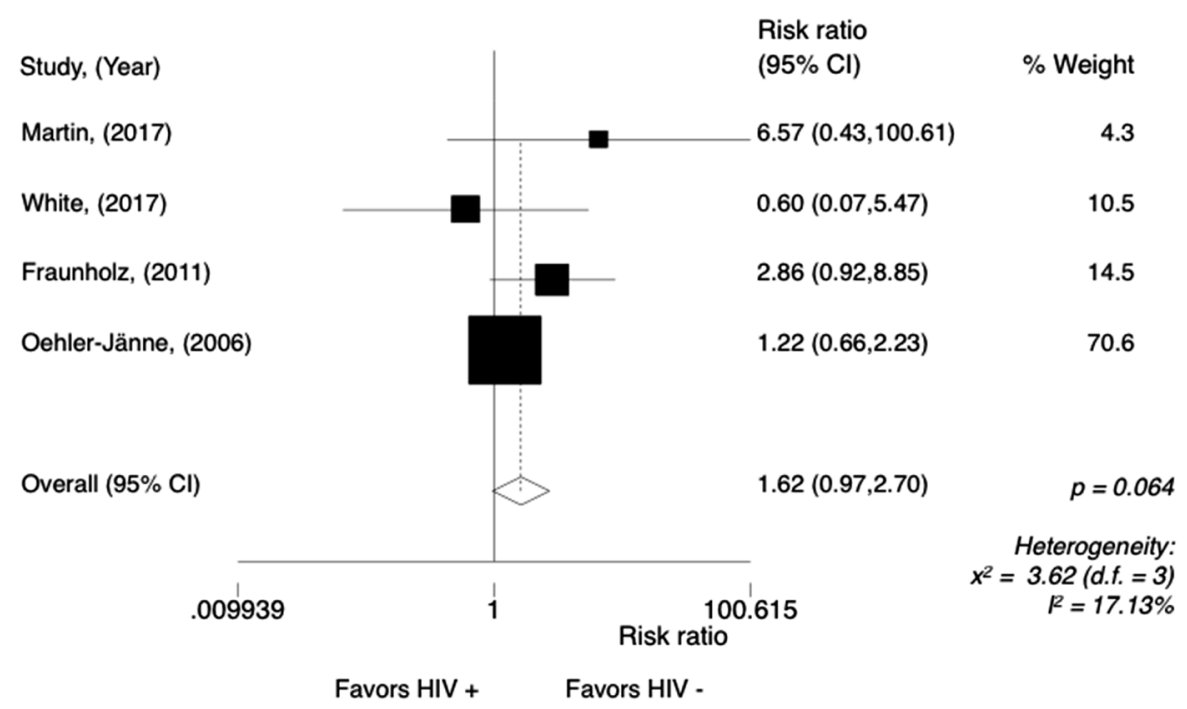

Figure 4 Forest plot of G3/4 thrombocytopenia in comparative studies.

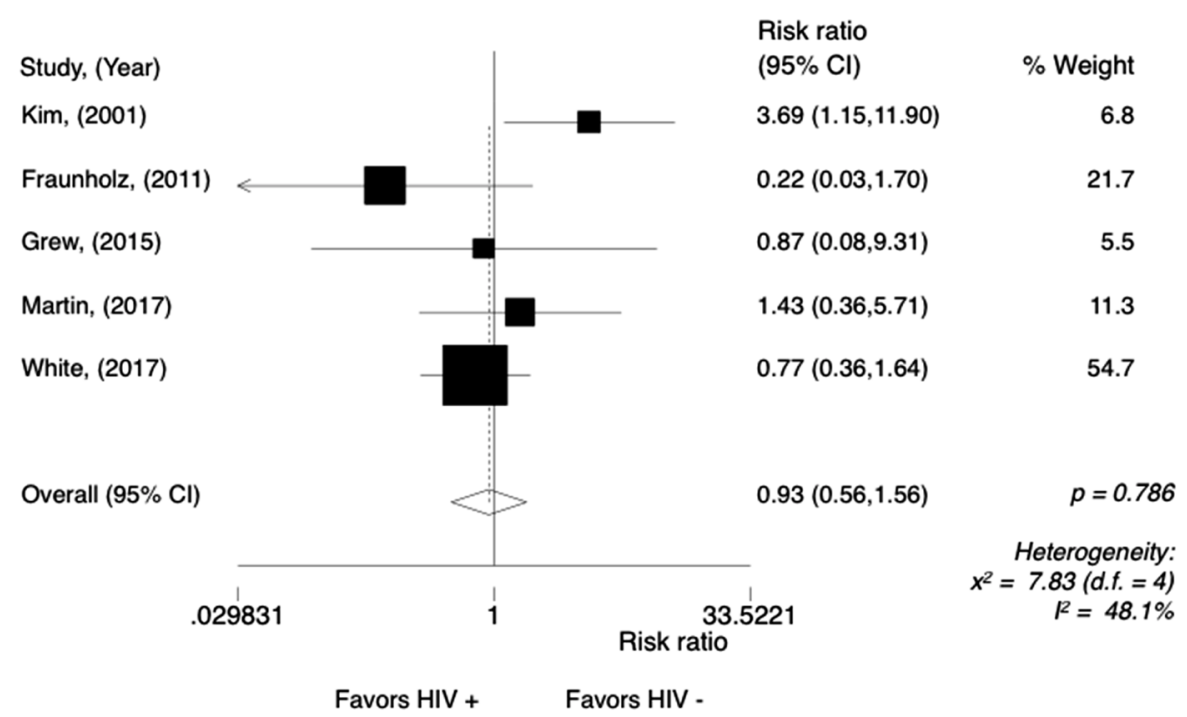

Figure 5 Forest plot of gastrointestinal G3/4 toxicities in comparative studies.

was performed in comparative studies $(\mathrm{N}=8)$, reporting data from 801 patients. The analysis (Figure 8 ) showed a worse 3 -year OS rate for $\mathrm{HIV}$-positive patients, with a RR of 1.77 (95\% CI, 1.35-2.32; $\mathrm{P}<0.001 ; \mathrm{I}^{2}=6 \%$ ). Random effect analysis is shown in Figure $S 6$.

The overall 5 -year survival rate ranged from $88 \%$ to $20 \%$ in the HIV-positive patients and from $84 \%$ to $65 \%$ in the HIV-negative patients. The meta-analysis for overall 5 -year survival rate was performed in comparative studies $(\mathrm{N}=6)$, reporting data from 637 patients (Figure 9). The 5-year OS rate was significantly worse for HIV-positive patients, with a RR of 1.39 (95\% CI, 1.04-1.85, P=0.024; $\left.\mathrm{I}^{2}=8.25 \%\right)$. Random effect analysis is shown in Figure S7.

Nine studies evaluated cancer-specific survival rates at 3 and 5 years. Martin et al. [2017] showed a statistically significant different in favor of HIV-negative patients, with a 5 -year specific cancer survival of $80.5 \%$ in HIV-positive vs. 93.8 in $\mathrm{HIV}$-negative group $(\mathrm{P}=0.029)$ (2). Ten studies reported on 5 -year DFS, and it ranged from $74 \%$ to $35 \%$ in the HIV-positive group and from $90 \%$ to $74 \%$ in the 


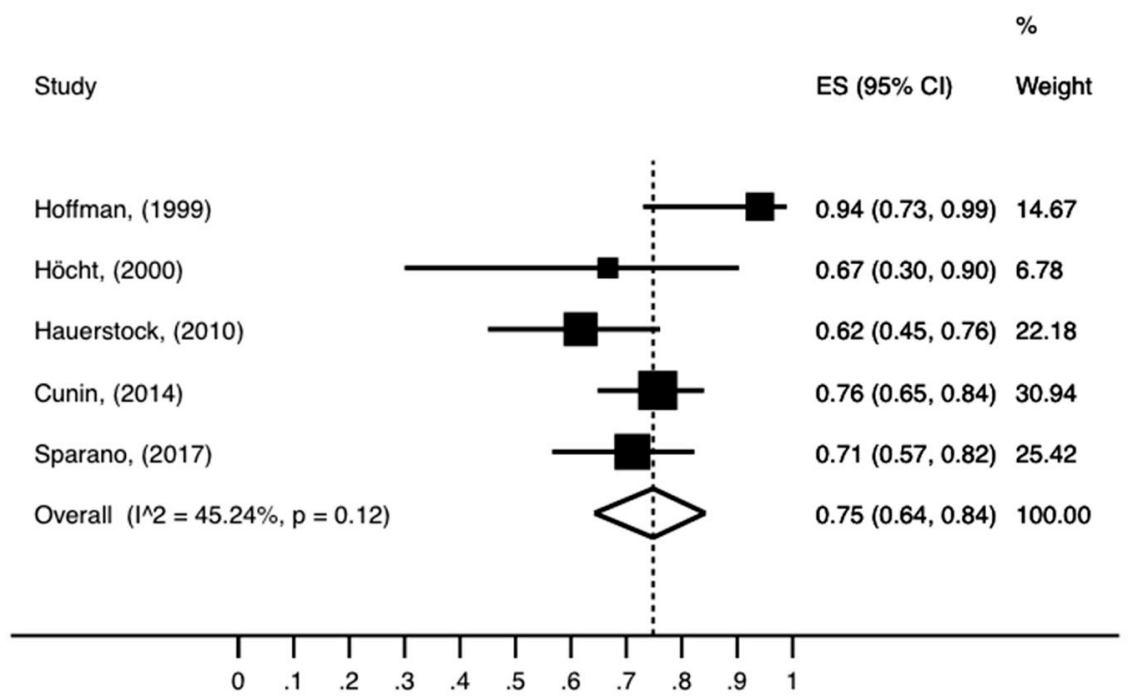

Figure 6 Pooled analysis of 3-year disease survival rate in non- comparative studies.

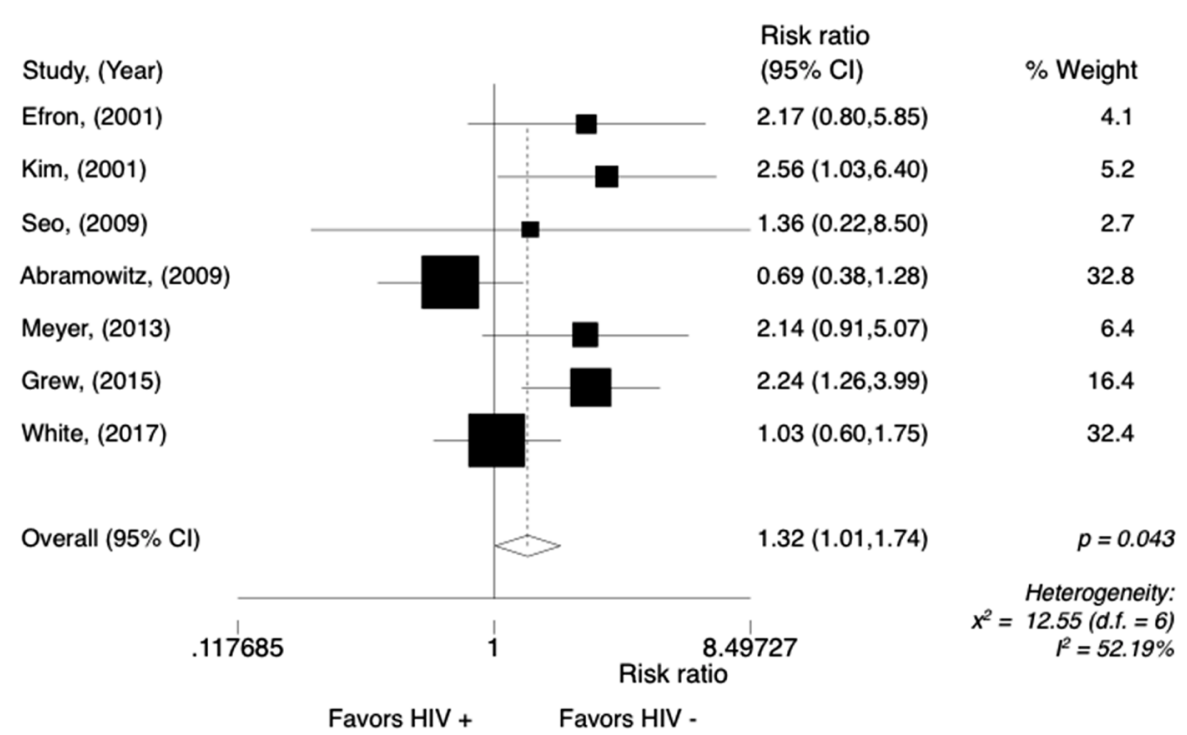

Figure 7 Forest plot of disease free survival rate at 3 years in comparative studies.

HIV-negative group. Oehler-Jänne et al. [2008] observed that the 5-year DFS survival rate was significantly higher for HIV-negative patients: 74\% (95\% CI, 64-85\%) vs. 35\% (95\% CI, 4-66\%; P=0.03) (20). Thirteen studies evaluated the rate of distance relapses at 5 and 3 years. In the HIVpositive group, distance relapse at 5 and 3 years ranged from none up to $14.3 \%$ and from none to $43 \%$, respectively. In the HIV-negative group, it ranged from $3 \%$ to $16 \%$ and $6 \%$ to $17 \%$, respectively. Ten studies evaluated local recurrence rates. The 5 -year local recurrence rate in HIV- positive patients ranged from $62 \%$ to $11 \%$ and in HIV patients, from $22 \%$ to 0 . Oehler-Jänne et al. [2006] showed a significant lower local recurrence rate at 5 years for the HIV-negative group, 0 vs. 30\%, (P=0.03) (21).

In 10 studies the clinical complete response after 6 months was seen in $60 \%$ to $100 \%$ of HIV-positive patients and in $75 \%$ to $100 \%$ of $\mathrm{HIV}$-negative patients. In 12 studies, the response rate was evaluated after 2 months of treatment, with complete responses seen in $50 \%$ to $85 \%$ for HIV-positive and in $41 \%$ to $93 \%$ for HIV-negative patients. 


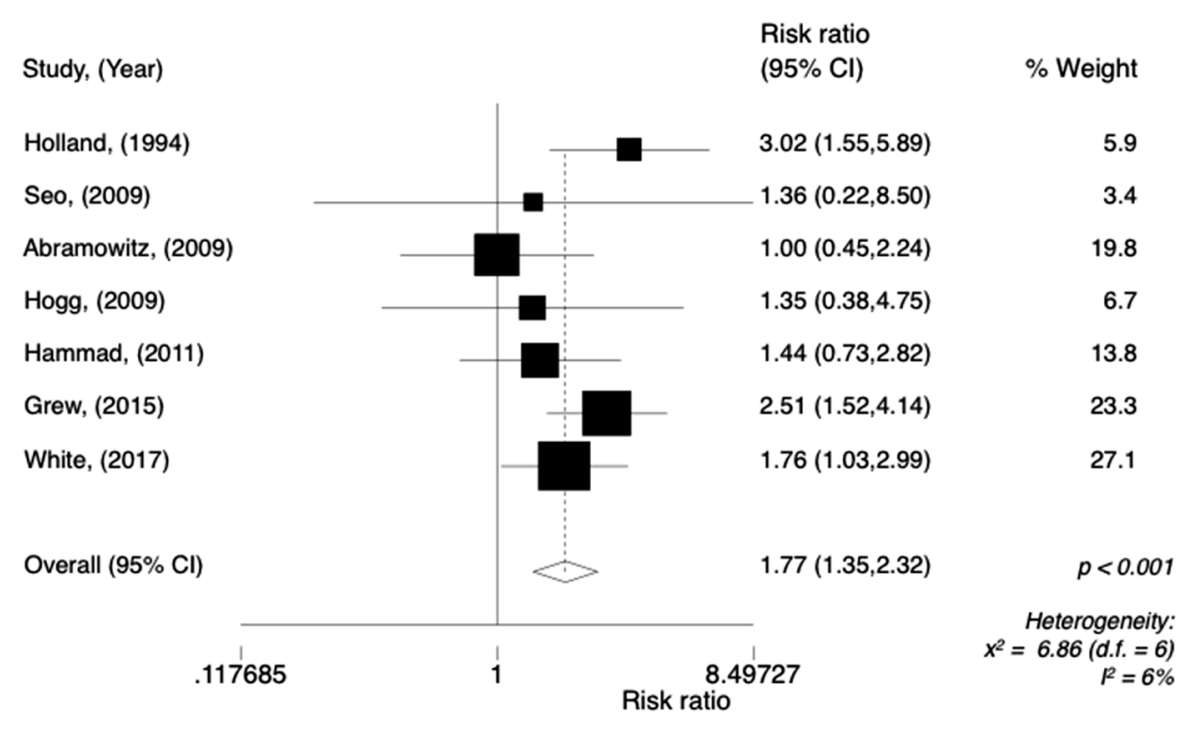

Figure 8 Forest plot of 3 -year overall survival rate in comparative studies.

\begin{tabular}{|c|c|c|}
\hline Study, (Year) & $\begin{array}{l}\text { Risk ratio } \\
(95 \% \mathrm{Cl})\end{array}$ & $\%$ Weight \\
\hline Oehler-Jänne, (2006) & $0.99(0.36,2.70)$ & 10.0 \\
\hline Oehler-Jänne, (2008) & $1.16(0.71,1.88)$ & 34.5 \\
\hline Fraunholz, (2011) & $1.26(0.55,2.90)$ & 13.3 \\
\hline Munoz-Bongrand, (2011) & $-3.90(1.48,10.29)$ & 6.5 \\
\hline Wieghard, (2016) & $1.35(0.61,3.02)$ & 11.5 \\
\hline Martin, ( 2017) & $1.30(0.71,2.38)$ & 24.2 \\
\hline Overall $(95 \% \mathrm{Cl})$ & $1.39(1.04,1.85)$ & $p=0.024$ \\
\hline .097213 & 2867 & $\begin{array}{r}\left.x^{2}=5.45 \text { (d.f. }=5\right) \\
\quad l=8.25 \%\end{array}$ \\
\hline
\end{tabular}

Figure 9 Forest plot of 5 -year overall survival rate in comparative studies.

Vatra et al. [2002] observed higher complete response rate in the HIV-negative group ( $88 \%$ vs. $50 \%, \mathrm{P}>0.05)$ (22).

The pooled analysis of colostomy-free survival rate at 3 years (Figure 10), which was performed in noncomparative studies, with a total of 793 patients, was $71 \%$ (95\% CI, 0.60-0.80; $\mathrm{P}<0.01 ; \mathrm{I}^{2}=63.70 \%$ ).

Regarding assessment of potential publication bias neither comparative nor non-comparative suggested publication bias for 3-year DFS or OS rates, as depicted in (Figures 11,12), respectively.

\section{Discussion}

This comprehensive systematic review and meta-analysis of uncontrolled studies from the HAART era shows that HIV-positive patients with localized SCCA treated with 


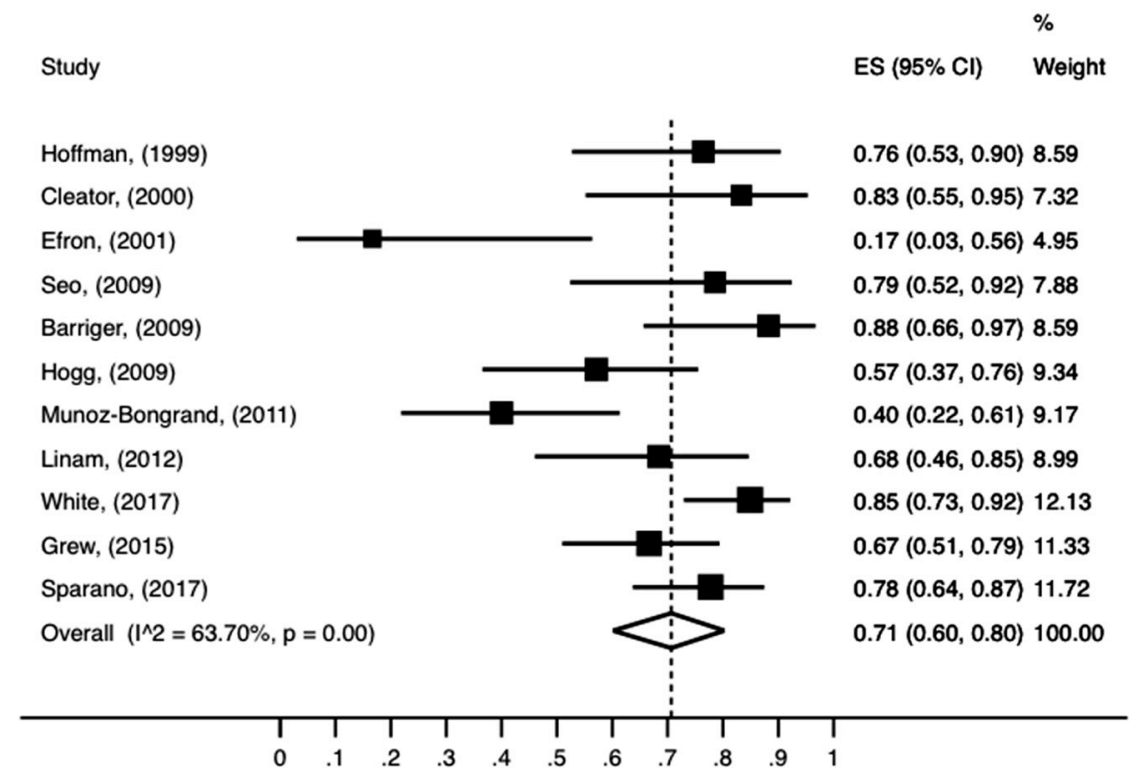

Figure 10 Forest plot of non-comparative studies of colostomy free survival 3-year analysis.
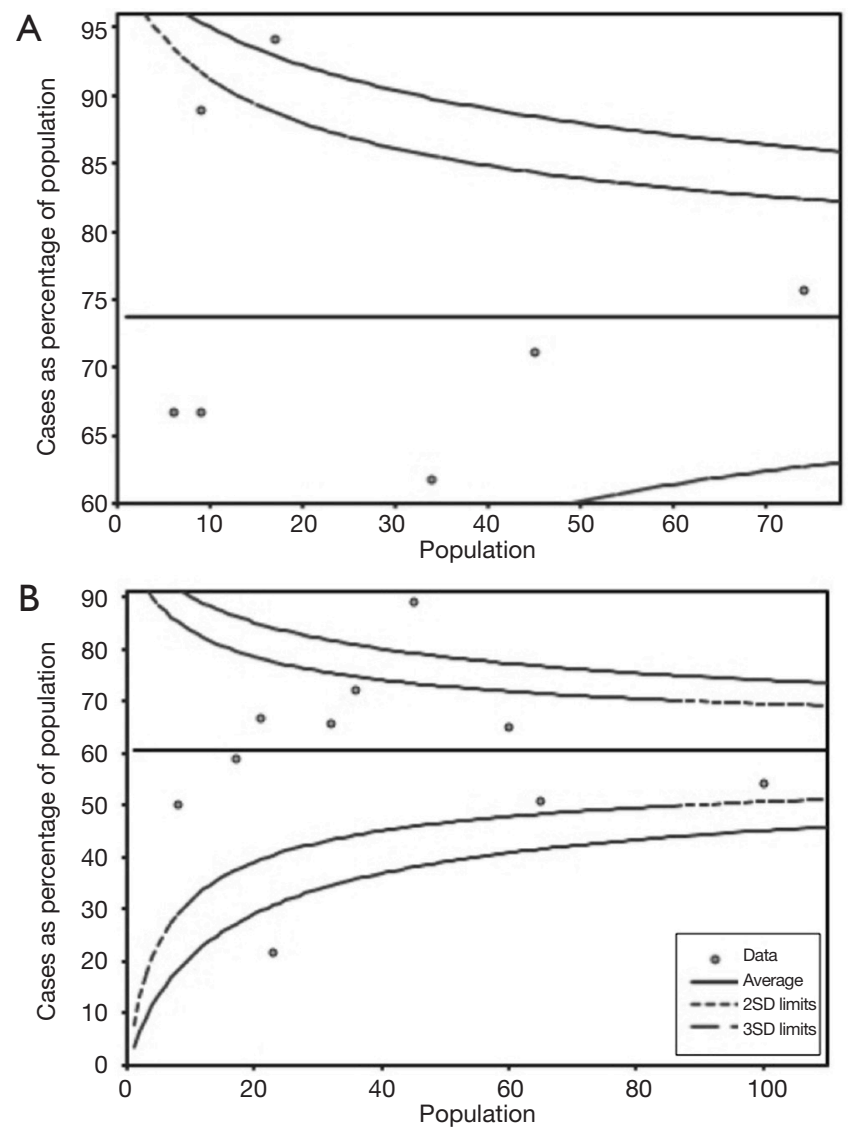

Figure 11 Funnel plots with pseudo $95 \%$ confidence limits. (A) 3-year disease free survival; (B) 3-year overall survival.

(C) Journal of Gastrointestinal Oncology. All rights reserved.
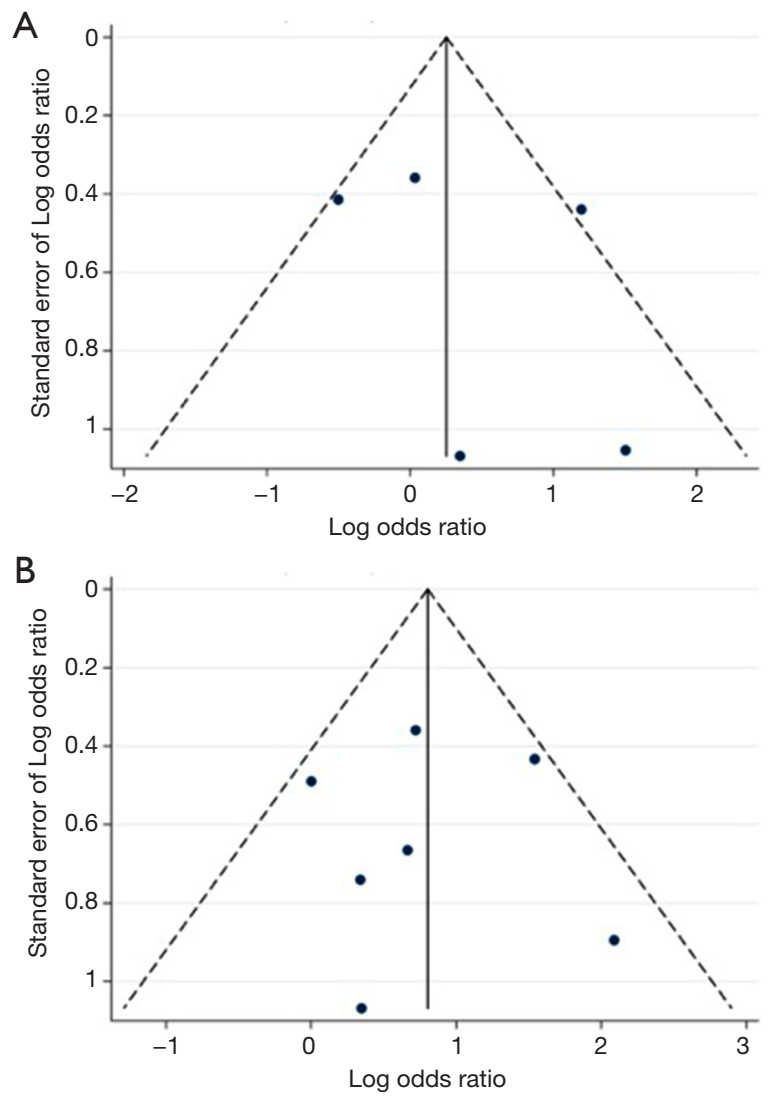

Figure 12 Funnel plots for proportion in non-comparative studies. (A) Represents 3-year disease free survival; (B) represents 3-year overall survival. 
chemoradiation experienced significantly worse 3-year DFS rate, 3- and 5-year OS rates, and enhanced risk of severe cutaneous toxicity, leukopenia and thrombocytopenia.

The exact reasons why HIV-positive patients with SCCA have worse treatment outcomes are unknown. We speculate that HIV-positive patients have lower bone marrow reserve (23) as a result of HIV infection, antiretroviral therapies $(24,25)$ and myelosuppressive prophylactic antibiotics, e.g., sulfamethoxazole/trimethoprim, what contributes to more pronounced myelosuppression from chemotherapy. This consequently leads to more dosereductions and treatment interruptions and ultimately less dose-intensity and reduced efficacy from CRT. Indeed, despite the variability in radiation techniques across time and studies, different methods to quantify and classify toxicities, and that most patients included in the pooled analyses presented CD4 count above 200 U/L, we observed that HIV-positive individuals were more likely to develop G3/4 leukopenia and thrombocytopenia. Unfortunately, the length and extent of myelosuppression could not be extracted from studies.

We also observed higher risk of dermatological toxicities (mostly represented by radiation-induced dermatitis) among HIV-positive patients (26). A possible explanation is that protease inhibitors used in HAART can enhance radio sensitivity, since they are cell-cycle inhibitors that could contribute to radiation-induced apoptosis $(2,27,28)$.

The inferior OS rates demonstrated in the HIV-positive group could have been confounded by deaths from AIDSrelated causes. Unfortunately, only two studies evaluated cancer-specific survival in HIV populations to properly tease out causes of deaths in these patients (29). However, HIV infection-related deaths do not solely explain the inferior 3 -year DFS rate observed in this group. Actually, local and distal recurrence rates for SCCA HIV-positive patients were numerically higher. On the other hand, our pooled analyses of rates of 3-year DFS and 3-year colostomy-free survival in non-comparative studies were $75 \%$, and $71 \%$, respectively, which are quite similar to that reported by the recent ACTII phase III trial, especially considering that both ACT-II trial and our meta-analysis included about $30 \%$ of patients with clinically node-positive SCCA. However, despite the similarity of our above findings with those described in the ACT-II phase III trial, indirect comparisons of studies' results should not be made. Higher rates of local recurrence could also be consequent to persistent HPV infection in HIV-positive patients (30-32). In this regard, the effects of the HPV vaccination on the incidence and cure rates of
SCCA in HIV-positive patients are eagerly awaited.

The interaction of the microenvironment and tumor has gained great interest recently. Specifically, the manipulation of the immune system by immune checkpoint inhibitors has changed the natural history of many neoplasms (33,34). Recently, Guihot et al. [2007] reported the case of a patient with metastatic non-small cell lung cancer and chronic HIV infection treated with nivolumab, (an anti-PDL1 antibody) (35). The patient presented a deep and sustained reduction in the HIV reservoir (35). The mechanism under this phenomenon was, in part, due to restoration of healthy and active HIV-specific CD8 T lymphocytes $(34,35)$. Interestingly a phase II trial with nivolumab in 39 patients with chemo-refractory metastatic anal cancer demonstrated that nine patient (24\%) achieved objective responses, with two being complete responses (36). Median progression-free survival was 4.1 months and median OS was 11.5 months. More and more immunotherapy will be part of the treatment of patients with cancer and the triplet of anal cancer, HIV and immune response is a fascinating research area to be explored. Despite being rare, the biology of SCCA in the presence of HIV infection should be better understood to revert the worse prognosis seen after convention CRT and novel agents, especially immunotherapy, should be also evaluated in the treatment of localized disease.

Limitations of our study should be noted. Our data were extracted from publications what prevented us from running analyses of time-to-event endpoints, subgroups based on type radiotherapy technique, chemotherapy regimen, performing adjusted analyses or exploring more detailed information on adverse events. Additionally, the types and doses of chemotherapy and radiotherapy varied across studies, as well as the rates and criteria to recommend reduction or delays in treatment or to grade toxicities. Those characteristics could justify the heterogeneity detected by some analyses and the large ranges of certain frequencies. An important issue to be pointed out is the overall poor quality of the studies included, which are likely associated with selection bias (inherent to retrospective studies) and observational bias (investigators may have monitored HIV-positive patients more closely and/ or may have more likely attributed toxicity relationship to the treatment than to the cancer, overestimating the rate of adverse events in this group). Although potential publications bias could not be demonstrated by the funnel plots, it is not possible to grant that they were completely absent, particularly when working with retrospective 
published data. We decided not to perform a formal quality assessment of the eligible studies because this would be redundant. Yet we still considered appropriate to perform the pooled analyses because, despite all limitations; and to our knowledge this is the best evidence on treatment outcomes for HIV-positive patients with localized SCCA.

Although HIV infection is associated with worse prognosis among patients with SCCA, no distinction concerning treatment and HIV status is addressed by most of current guidelines (37). Based on our findings we suggest that, for now, HIV-positive patients with localized SCCA be treated with CRT using less toxic radiotherapy, such as Intensity-Modulated Radiation Therapy, and chemotherapy with infusional $5 \mathrm{FU} /$ capecitabine and cisplatin, as per the ACT-II phase III trial (38). In the ACT-II trial the efficacy of the cisplatin-based regimen was similar to the Nigro regimen, but cisplatin offers less myelosuppression than MMC (the rate of G3/4 was $26 \%$ vs. $16 \%$, respectively). Given that most studies included in the present analyses used MMC and conventional radiotherapy techniques, it is possible that less toxicity is seen in routine practice as more patients are being treated with cisplatin and IMRT because of the worldwide shortage of MMC. Therefore, future observational studies should be conducted to quantify the toxicities associated with cisplatin-based CRT in HIV-positive SCCA patients. Another important recommendation is to have an HIV medical specialist involved in the care of these patients, particularly with respect to the decision on the type of HAART and accompanying prophylactic antibiotics, discussing whether less myelosupressive agents or those with less potential for drug-drug interactions can be used.

\section{Conclusions}

In this systematic review and meta-analyses, we have demonstrated that HIV-positive patients with localized SCCA under HAART and who received definitive chemoradiation presented higher risk of severe hematological and cutaneous adverse events and inferior DFS and OS rates in comparison with HIV-negative individuals. Despite the limitations of our study, it represents a good quality source of evidence to set the foundation for epidemiological and interventional future studies on HIV-positive patients with localized SCCA.

\section{Acknowledgements}

None.

\section{Footnote}

Conflicts of Interest: The authors have no conflicts of interest to declare.

\section{References}

1. Silverberg MJ, Lau B, Achenbach CJ, et al. Cumulative incidence of cancer among persons with HIV in North America: A cohort study. Ann Intern Med 2015;163:507-18.

2. Martin D, Balermpas P, Fokas E, et al. Are there HIVspecific Differences for Anal Cancer Patients Treated with Standard Chemoradiotherapy in the Era of Combined Antiretroviral Therapy? Clin Oncol (R Coll Radiol) 2017;29:248-55.

3. Sparano JA, Lee JY, Palefsky J, et al. Cetuximab plus chemoradiotherapy for HIV-associated anal carcinoma: A phase II AIDS malignancy consortium trial. J Clin Oncol 2017;35:727-33.

4. Hauerstock D, Ennis RD, Grossbard M, et al. Efficacy and toxicity of chemoradiation in the treatment of $\mathrm{HIV}$-associated anal cancer. Clin Colorectal Cancer 2010;9:238-42.

5. Abramowitz L, Mathieu N, Roudot-Thoraval F, et al. Epidermoid anal cancer prognosis comparison among $\mathrm{HIV}+$ and HIV-patients. Aliment Pharmacol Ther 2009;30:414-21.

6. Colón-López V, Shiels MS, Machin M, et al. Anal cancer risk among people with $\mathrm{HIV}$ infection in the United States. J Clin Oncol 2018;36:68-75.

7. Souza KT, Pereira AA, Araujo RL, et al. Replacing 5-fluorouracil by capecitabine in localised squamous cell carcinoma of the anal canal: Systematic review and metaanalysis. Ecancermedicalscience 2016;10:699.

8. Munoz-Bongrand N, Poghosyan T, Zohar S, et al. Anal carcinoma in $\mathrm{HIV}$-infected patients in the era of antiretroviral therapy: A comparative study. Dis Colon Rectum 2011;54:729-35.

9. White EC, Khodayari B, Erickson KT, et al. Comparison of Toxicity and Treatment Outcomes in HIV-positive Versus HIV-negative Patients With Squamous Cell 
Carcinoma of the Anal Canal. Am J Clin Oncol 2017;40:386-92.

10. Lorenz HP, Wilson W, Leigh B, et al. Squamous cell carcinoma of the anus and HIV infection. Dis Colon Rectum 1991;34:336-8.

11. Chiao EY, Giordano TP, Richardson P, et al. Human immunodeficiency virus-associated squamous cell cancer of the anus: epidemiology and outcomes in the highly active antiretroviral therapy era. J Clin Oncol 2008;26:474-9.

12. Place RJ, Gregorcyk SG, Huber PJ, et al. Outcome analysis of $\mathrm{HIV}$-positive patients with anal squamous cell carcinoma. Dis Colon Rectum 2001;44:506-12.

13. Kim JH, Sarani B, Orkin BA, et al. HIV-positive patients with anal carcinoma have poorer treatment tolerance and outcome than HIV-negative patients. Dis Colon Rectum 2001;44:1496-502.

14. Höcht S, Wiegel T, Runkel N, et al. Cancer of the Anal Canal and HIV Infection: Toxicity and Results of Organ Preservation with Radiochemotherapy or Radiotherapy. Onkologie 2000;23:134-7.

15. Wexler A, Berson AM, Goldstone SE, et al. Invasive anal squamous-cell carcinoma in the HIV-positive patient: Outcome in the era of highly active antiretroviral therapy. Dis Colon Rectum 2008;51:73-81.

16. Panic N, Leoncini E, De Belvis G, et al. Evaluation of the endorsement of the preferred reporting items for systematic reviews and meta-analysis (PRISMA) statement on the quality of published systematic review and metaanalyses. PLoS One 2013;8:e83138.

17. Mavridis D, Salanti G. Exploring and accounting for publication bias in mental health: A brief overview of methods. Evid Based Ment Health 2014;17:11-5.

18. Mavridis D, Salanti G. How to assess publication bias: Funnel plot, trim-and-fill method and selection models. Evid Based Ment Health 2014;17:30.

19. Nyaga VN, Arbyn M, Aerts M. Metaprop: A Stata command to perform meta-analysis of binomial data. Arch Public Health 2014;72:39.

20. Oehler-Jänne C, Huguet F, Provencher S, et al. HIVspecific differences in outcome of squamous cell carcinoma of the anal canal: a multicentric cohort study of HIVpositive patients receiving highly active antiretroviral therapy. J Clin Oncol 2008;26:2550-7.

21. Oehler-Jänne C, Seifert B, Lutolf UM, et al. Local tumor control and toxicity in $\mathrm{HIV}$-associated anal carcinoma treated with radiotherapy in the era of antiretroviral therapy. Radiat Oncol 2006;1:29.

22. Vatra B, Sobhani I, Aparicio T, et al. Anal canal squamous- cell carcinomas in HIV positive patients: clinical features, treatments and prognosis. Gastroenterol Clin Biol 2002;26:150-6.

23. Chadha M, Rosenblatt EA, Malamud S, et al. Squamouscell carcinoma of the anus in HIV-positive patients. Dis Colon Rectum 1994;37:861-5.

24. Fraunholz I, Weiss C, Eberlein K, et al. Concurrent chemoradiotherapy with 5-fluorouracil and mitomycin $\mathrm{C}$ for invasive anal carcinoma in human immunodeficiency virus-positive patients receiving highly active antiretroviral therapy. Int J Radiat Oncol Biol Phys 2010;76:1425-32.

25. Martellotta F, Berretta M, Cacopardo B, et al. Clinical presentation and outcome of squamous cell carcinoma of the anus in HIV-Infected patients in the HAARTEra: A gicat experience. Eur Rev Med Pharmacol Sci 2012;16:1283-91.

26. Linam JM, Chand RR, Broudy VC, et al. Evaluation of the impact of HIV serostatus, tobacco smoking and CD4 counts on epidermoid anal cancer survival. Int J STD AIDS 2012;23:77-82.

27. Fraunholz I, Rabeneck D, Gerstein J, et al. Concurrent chemoradiotherapy with 5-fluorouracil and mitomycin $\mathrm{C}$ for anal carcinoma: Are there differences between HIV-positive and HIV-negative patients in the era of highly active antiretroviral therapy? Radiother Oncol 2011;98:99-104.

28. Blazy A, Hennequin C, Gornet JM, et al. Anal carcinomas in HIV-positive patients: High-dose chemoradiotherapy is feasible in the era of highly active antiretroviral therapy. Dis Colon Rectum 2005;48:1176-81.

29. Alfa-Wali M, Allen-mersh T, Antoniou A, et al. Chemoradiotherapy for anal cancer in HIV patients causes prolonged CD4 cell count suppression. Ann Oncol 2012;23:141-7.

30. Fraunholz IB, Haberl A, Klauke S, et al. Long-term effects of chemoradiotherapy for anal cancer in patients with HIV infection: oncological outcomes, immunological status, and the clinical course of the HIV disease. Dis Colon Rectum 2014;57:423-31.

31. Rovelli C, Poli A, Galli L, et al. Presence of multiple genotypes in subjects with HPV-16 infection is highly associated with anal squamous intraepithelial lesions in HIV-1 infected males. PLoS One 2017;12:e0186367.

32. Nadal SR, Horta SH, Calore EE, et al. Outcome of treatment of anal squamous cell carcinoma and its precursor in HIV-infected patients. Rev Assoc Med Bras 2007;53:365-9.

33. Motzer RJ, Escudier B, McDermott DF, et al. Nivolumab 
versus Everolimus in Advanced Renal-Cell Carcinoma. N Engl J Med 2015;373:1803-13.

34. Reck M, Rodríguez-Abreu D, Robinson AG, et al. Pembrolizumab versus Chemotherapy for PD-L1Positive Non-Small-Cell Lung Cancer. N Engl J Med 2016;375:1823-33.

35. Guihot A, Marcelin AG, Massiani MA, et al. Drastic decrease of the HIV reservoir in a patient treated with nivolumab for lung cancer. Ann Oncol 2018;29:517-8.

36. Morris VK, Salem ME, Nimeiri H, et al. Nivolumab for previously treated unresectable metastatic anal cancer

Cite this article as: Camandaroba MP, Araujo RL, Silva VS, Mello CA, Riechelmann RP. Treatment outcomes of patients with localized anal squamous cell carcinoma according to HIV infection: systematic review and meta-analysis. J Gastrointest Oncol 2019;10(1):48-60. doi: 10.21037/jgo.2018.10.08
(NCI9673): a multicentre, single-arm, phase 2 study. Lancet Oncol 2017;18:446-53.

37. Glynne-Jones R, Nilsson PJ, Aschele C, et al. Anal cancer: ESMO-ESSO-ESTRO clinical practice guidelines for diagnosis, treatment and follow-up. Ann Oncol 2014;25 Suppl 3:iii10-20.

38. James RD, Glynne-Jones R, Meadows HM, et al. Mitomycin or cisplatin chemoradiation with or without maintenance chemotherapy for treatment of squamous-cell carcinoma of the anus (ACT II): A randomised, phase 3, open-label, 2×2 factorial trial. Lancet Oncol 2013;14:516-24. 


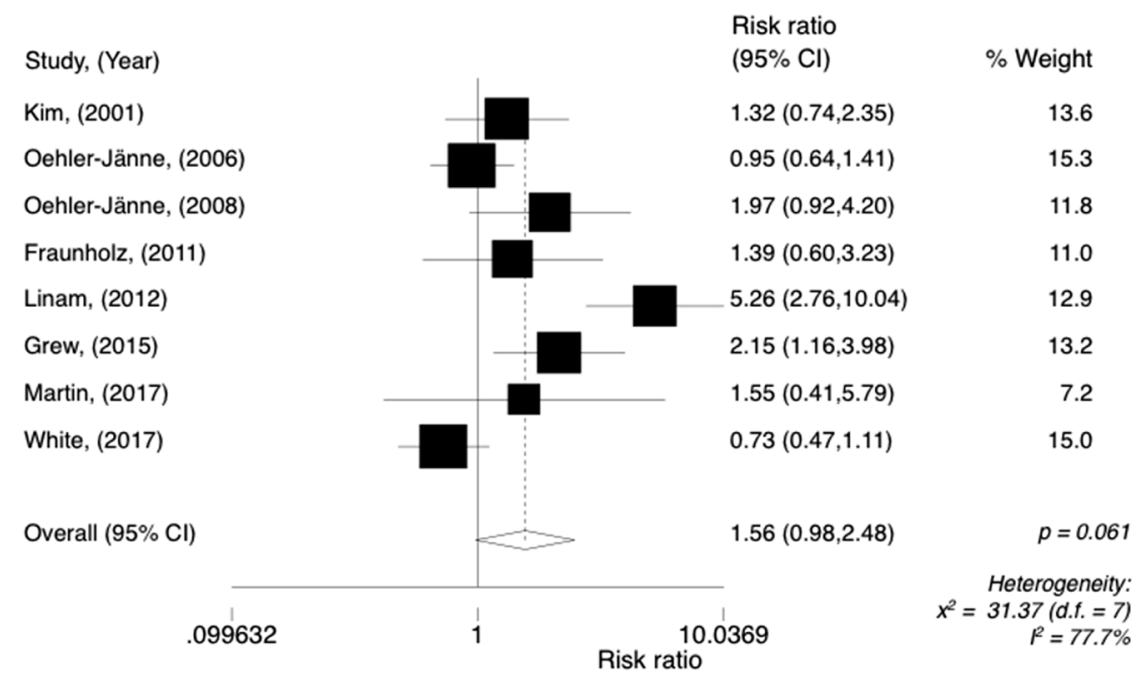

Favors HIV $+\quad$ Favors HIV -

Figure S1 Random effect analysis G3/4 cutaneous toxicities.

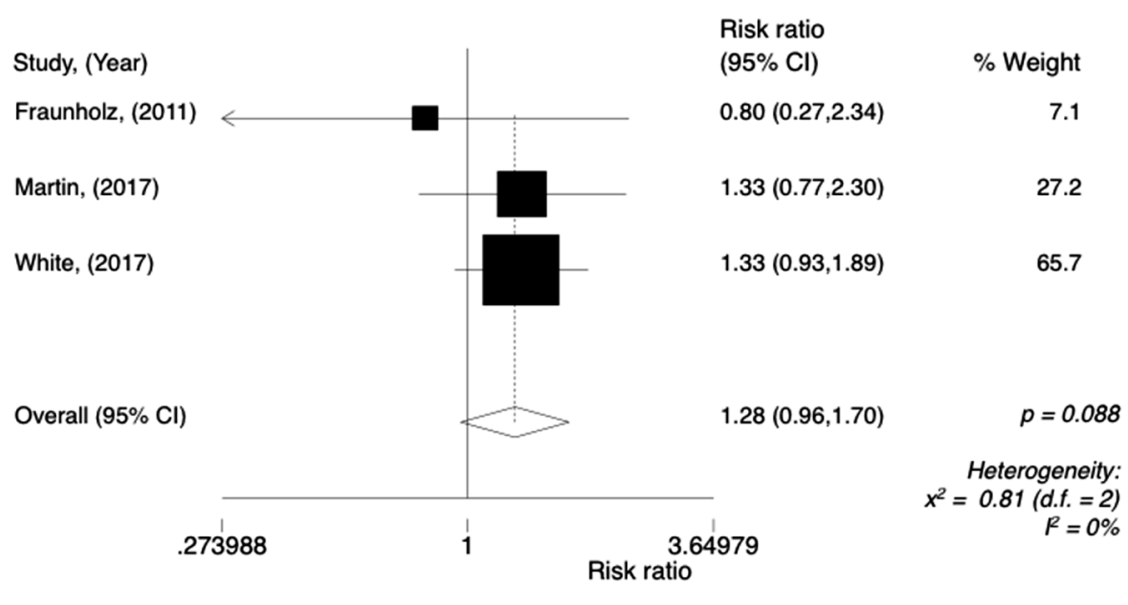

Favors HIV + Favors HIV .

Figure S2 Random effect analysis G3/4 leukopenia.

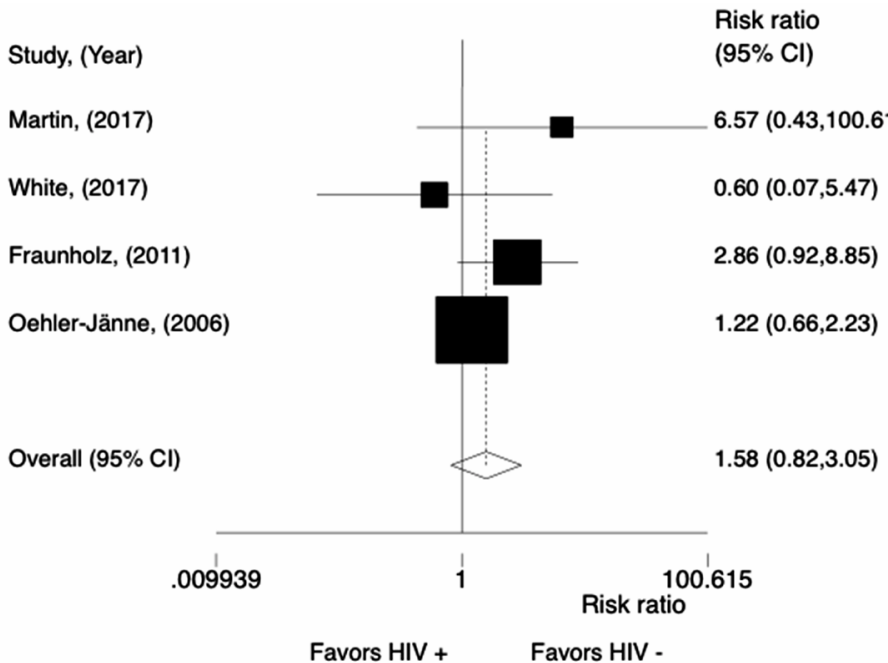

Favors HIV + Favors HIV -

Figure S3 Thrombocitopenia-randomic effect. 


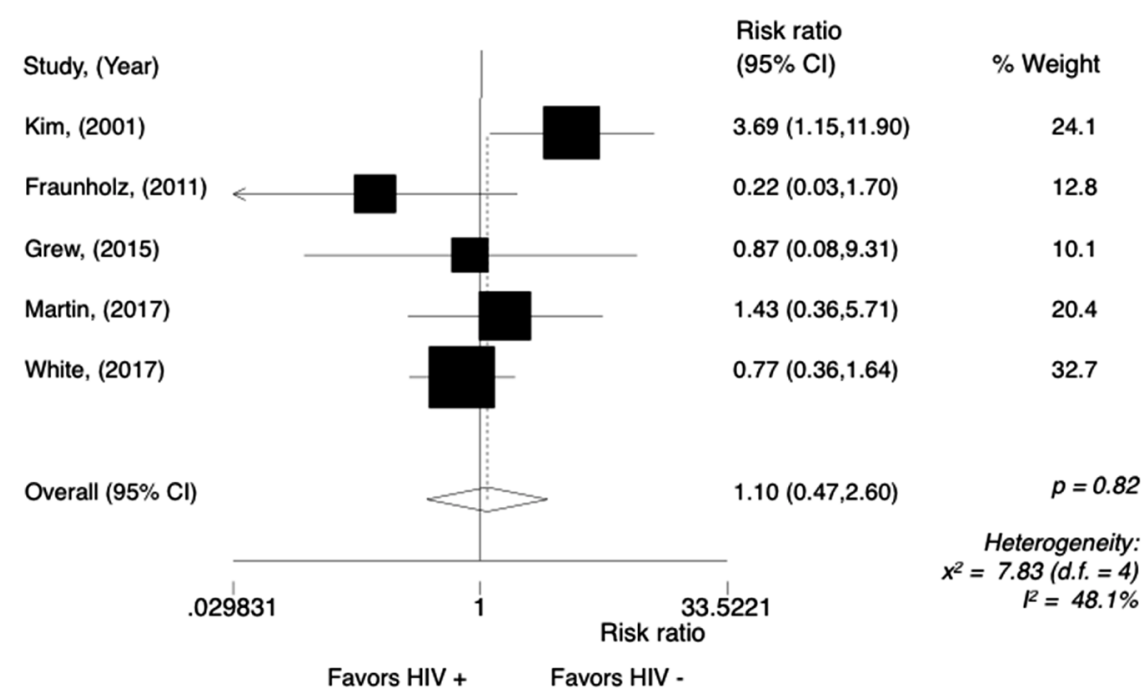

Figure S4 Random effect analysis G3/4 gastrointestinal toxicities.

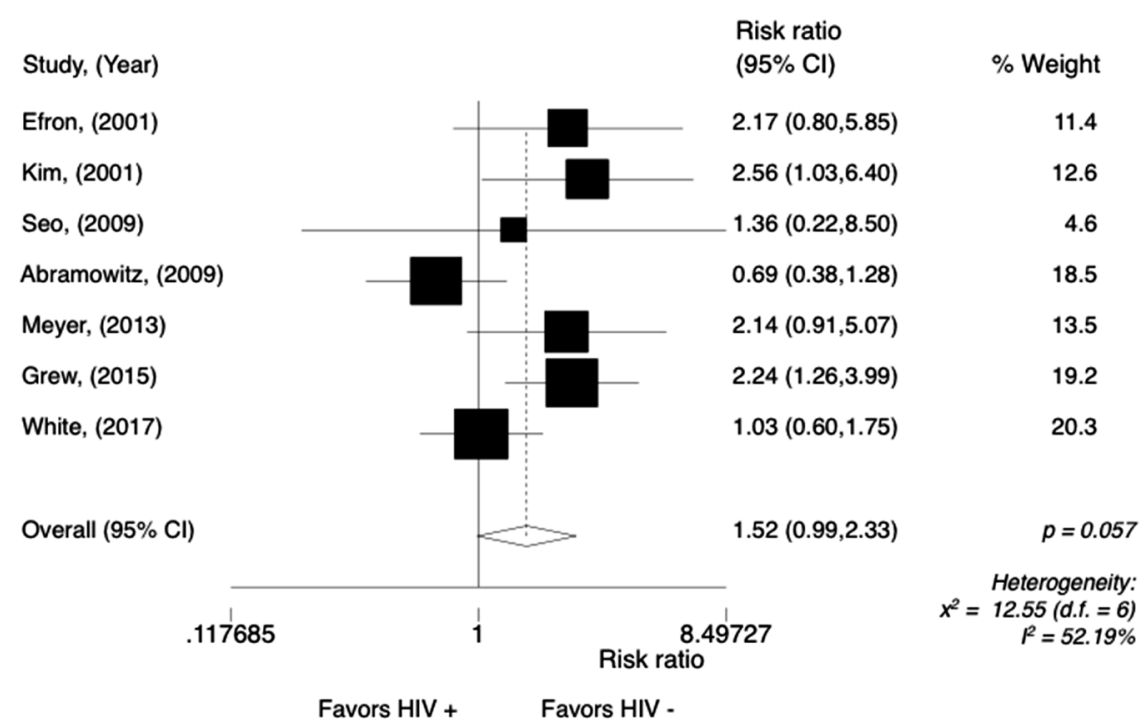

Figure S5 Random effect analysis 3-year disease free survival.

\begin{tabular}{|c|c|c|}
\hline Study, (Year) & $\begin{array}{l}\text { Risk ratio } \\
(95 \% \mathrm{Cl})\end{array}$ & $\%$ Weight \\
\hline Holland, (1994) & $3.02(1.55,5.89)$ & 12.8 \\
\hline Kim, (2001) & $1.11(0.57,2.14)$ & 13.1 \\
\hline Vatra, (2002) & $1.92(0.74,4.95)$ & 6.8 \\
\hline Seo, (2009) & $-1.36(0.22,8.50)$ & 1.9 \\
\hline Abramowitz, (2009) & $1.00(0.45,2.24)$ & 9.1 \\
\hline Hogg, (2009) & $1.35(0.38,4.75)$ & 4.0 \\
\hline Hammad, (2011) & $1.44(0.73,2.82)$ & 12.6 \\
\hline Grew, (2015) & $2.51(1.52,4.14)$ & 20.7 \\
\hline White, (2017) & $1.76(1.03,2.99)$ & 18.9 \\
\hline Overall $(95 \% \mathrm{Cl})$ & $1.75(1.36,2.26)$ & $p<0.001$ \\
\hline. & & $\begin{array}{r}\text { Heterogeneity: } \\
x^{2}=8.98(d . f .=8) \\
R^{2}=10.9 \%\end{array}$ \\
\hline
\end{tabular}

Favors HIV $+\quad$ Favors HIV -

Figure S6 Random effect analysis 3-year overall survival. 


\begin{tabular}{|c|c|c|}
\hline Study, (Year) & $\begin{array}{l}\text { Risk ratio } \\
(95 \% \mathrm{Cl})\end{array}$ & \% Weight \\
\hline Oehler-Jänne, (2006) & $0.99(0.36,2.70)$ & 8.8 \\
\hline Oehler-Jänne, (2008) & $1.16(0.71,1.88)$ & 33.1 \\
\hline Fraunholz, (2011) & $1.26(0.55,2.90)$ & 12.6 \\
\hline Munoz-Bongrand, (2011) & $-3.90(1.48,10.29)$ & 9.4 \\
\hline Wieghard, (2016) & $1.35(0.61,3.02)$ & 13.5 \\
\hline Martin, ( 2017) & $1.30(0.71,2.38)$ & 22.6 \\
\hline Overall (95\% Cl) & $1.36(1.00,1.84)$ & $p=0.051$ \\
\hline
\end{tabular}

Figure S7 Random effect analysis 5-year overall survival. 